\title{
Influence of temperature on structural and magnetic properties of $\mathrm{Co}_{0.5} \mathrm{Mn}_{0.5} \mathrm{Fe}_{2} \mathrm{O}_{4}$ ferrites
}

\author{
S M RAMAY ${ }^{1}$, MURTAZA SALEEM, S ATIQ, SAADAT A SIDDIQI², S NASEEM \\ and M SABIEH ANWAR ${ }^{1, *}$ \\ Centre of Excellence in Solid State Physics, University of the Punjab, Lahore 54590, Pakistan \\ ${ }^{1}$ School of Science and Engineering, Lahore University of Management Sciences (LUMS), Opposite Sector U, \\ DHA, Lahore 54792, Pakistan \\ ${ }^{2}$ Interdisciplinary Research Centre in Biomedical Materials, COMSATS IIT, Off Raiwind Road, Lahore, Pakistan
}

MS received 24 May 2009; revised 27 October 2010

\begin{abstract}
Co}_{0.5} \mathrm{Mn}_{0.5} \mathrm{Fe}_{2} \mathrm{O}_{4}$ ferrites have been synthesized using a single-step sol-gel auto-combustion method in which the metal nitrate (MN)-to-citric acid (CA) ratio was adjusted to 0.5:1 and pH to 7, respectively. The structural and magnetic properties of as-burnt and annealed samples were studied as a function of temperature. The inverse spinel structure was confirmed by X-ray diffraction (XRD) and crystallite size was estimated by the most intense peak (311) using Scherrer's formula. Contrary to earlier studies reported in the literature, both as-burnt and annealed samples exhibit crystalline behaviour. Room temperature magnetic properties were studied using vibrating sample magnetometer (VSM) with field strengths up to $\pm 10 \mathrm{kOe}$. Lattice constant and crystallite size increased as the annealing temperature was increased. However, the coercivity $\left(H_{c}\right)$ initially increased and then decreased with the increase of crystallite size. The variation in coercivity is ascribed to the transition from a multi-domain to a single-domain configuration.
\end{abstract}

Keywords. Sol-gel preparation; ferrites; crystallite size; coercivity.

\section{Introduction}

$\mathrm{CoFe}_{2} \mathrm{O}_{4}$ ferrites are considered a promising and technologically important material for high-density recording media due to their high coercivity $\left(H_{\mathrm{c}}\right)$, moderate saturation magnetization $\left(M_{\mathrm{s}}\right)$ and excellent chemical stability (Lee et al 1992). Metal-substituted cobalt ferrites are suitable for magneto-mechanical strain sensors and activator applications (Chen et al 1999). Many researchers have studied cobalt ferrites substituted with $\mathrm{Mn}$ and investigated their magnetic, magneto-optical and magnetomechanical properties (Zhou et al 2001; Paulsen et al 2004; Calton et al 2007a, b; Shobana et al 2009). Zhou et al (2001) reported that thin films of $\mathrm{CoFe}_{2} \mathrm{O}_{4}$ ferrites are promising for future generation magneto-optical recording media due to their large magneto-optical effect in the visible range and good corrosion resistance (Martens et al 1985; Suzuki and Yamazaki 1988; Bouet et al 1996) compared to rare-earth transition metal amorphous thin films (Daval and Bechevet 1994). Polycrystalline co-ferrites have large media noise (Abe and Gomi 1990) due to scattering of light at grain boundaries and irregular shape of the read-write domains. This problem can be reduced (Shimokawa et al 1996) if the grain size of the

\footnotetext{
*Author for correspondence (sabieh@lums.edu.pk)
}

polycrystalline material is of the nanometer scale, because nanosized grains can make the read-write domains more homogeneous and their boundaries rarely scatter visible wavelengths. Furthermore, the high Curie temperature of $\mathrm{CoFe}_{2} \mathrm{O}_{4}\left(520^{\circ} \mathrm{C}\right)$ poses problems for commercial disk writing. Therefore, it has been demonstrated that the incorporation of $\mathrm{Mn}$ in these ferrites could help reduce the Curie temperature in order to make them suitable for disk writing applications (Suzuki 1991; Srinivas and Shin 1996). Reasonably, low Curie temperatures are needed for disk writing applications so that a moderate power laser is able to achieve the temperatures necessary for small coercivity and easy magnetization reversal (Liu 2005).

In the present work, we synthesized $\mathrm{Co}_{0.5} \mathrm{Mn}_{0.5} \mathrm{Fe}_{2} \mathrm{O}_{4}$ ferrites using the sol-gel auto-combustion method that is a simple, rapid, inexpensive and single-step, yet novel, combining chemical, sol-gel and combustion processes (Mali and Ataie 2005). The as-burnt powder was calcined at different temperatures $\left(500,600,700,800\right.$ and $\left.900^{\circ} \mathrm{C}\right)$. The main objective of this work was to study the size effect on the structural and magnetic properties of $\mathrm{Co}_{0.5} \mathrm{Mn}_{0.5}$ $\mathrm{Fe}_{2} \mathrm{O}_{4}$ ferrites annealed at different temperatures. Besides, the sol-gel auto-combustion offers a particularly advantageous and highly reproducible means of synthesizing these ferrites with possible commercial applications. 


\section{Experimental}

Analytical grade ferric nitrate $\mathrm{Fe}\left(\mathrm{NO}_{3}\right)_{2} \cdot 9 \mathrm{H}_{2} \mathrm{O}$, cobalt nitrate $\mathrm{Co}\left(\mathrm{NO}_{3}\right)_{2} \cdot 6 \mathrm{H}_{2} \mathrm{O}$, manganese nitrate $\mathrm{Mn}\left(\mathrm{NO}_{3}\right)_{2}$. $4 \mathrm{H}_{2} \mathrm{O}$, citric acid $\mathrm{C}_{6} \mathrm{H}_{8} \mathrm{O}_{7}$ and ammonia were used as starting materials. Ferric nitrate, cobalt nitrate and manganese nitrate in the molar ratios $2: 0 \cdot 5: 0.5$ were dissolved in deionized water after adjusting the metal nitrate: citric acid ratio to $0 \cdot 5: 1 \cdot 0$. The mixed solution was neutralized to a $\mathrm{pH}$ value of 7 by adding liquid ammonia. The neutralized solution was then evaporated to dryness by heating at $100^{\circ} \mathrm{C}$ on a hot plate with continuous magnetic stirring. As the water evaporated, the solution became viscous and finally formed a highly viscous gel. Increasing the temperature up to $200^{\circ} \mathrm{C}$ led to the self-ignition of the gel. The dried gel burnt in a selfpropagating combustion reaction until all the gels were completely burnt out to form a voluminous and fluffy powder with a large surface area. Finally the as-burnt powder was annealed at different temperatures $\left(500-900^{\circ} \mathrm{C}\right)$. Experimentally it is observed that all the samples showed combustible behaviour and always burnt out completely to form a loose powder.

In order to characterize the as-burnt and annealed powder, X-ray diffraction (XRD) with $\mathrm{CuK} \alpha$ radiation (1.5406 $\AA$, D-MaxII-A X-ray diffractometer) was used to confirm the $\mathrm{Co}_{0.5} \mathrm{Mn}_{0.5} \mathrm{Fe}_{2} \mathrm{O}_{4}$ phase. Magnetic properties were measured at room temperature using Lakeshore's 7404 vibrating sample magnetometer.

\section{Results and discussion}

During the reaction, $\mathrm{N}_{2}, \mathrm{CO}_{2}$ and $\mathrm{H}_{2} \mathrm{O}$ are the evolved gases according to the combustion reaction (figure 1) as follows:

$$
\begin{aligned}
& 4 \mathrm{Fe}\left(\mathrm{NO}_{3}\right)_{3} \cdot 9 \mathrm{H}_{2} \mathrm{O}+\mathrm{Co}\left(\mathrm{NO}_{3}\right)_{2} \cdot 6 \mathrm{H}_{2} \mathrm{O}+\mathrm{Mn}\left(\mathrm{NO}_{3}\right)_{2} \cdot 4 \mathrm{H}_{2} \mathrm{O}+ \\
& 6 \mathrm{C}_{6} \mathrm{H}_{8} \mathrm{O}_{7} \cdot 2 \mathrm{H}_{2} \mathrm{O}+7 \mathrm{O}_{2} \rightarrow 2 \mathrm{Co}_{0.5} \mathrm{Mn}_{0.5} \mathrm{Fe}_{2} \mathrm{O}_{4}+ \\
& 82 \mathrm{H}_{2} \mathrm{O}+36 \mathrm{CO}_{2}+8 \mathrm{~N}_{2} .
\end{aligned}
$$

Figure 2 shows the XRD patterns of nanocrystalline $\mathrm{Co}_{0.5} \mathrm{Mn}_{0.5} \mathrm{Fe}_{2} \mathrm{O}_{4}$ ferrites that are as-burnt and samples annealed at different temperatures. Both as-burnt and annealed samples have a cubic spinel structure indexed with JCPDS card No. 22-1086. The $\mathrm{Fe}_{2} \mathrm{O}_{3}$ peak was observed at 700 and $800^{\circ} \mathrm{C}$, which may be due to the thermal instability during annealing but no extra peak could be found for samples annealed at $900^{\circ} \mathrm{C}$. The increase in intensity of different peaks as a function of temperature substantiates the improved crystallinity of the samples, as expected. The average crystallite size was estimated by considering the most intense peak (311) and using the Scherrer's formula (Cullity and Stock 2007)

$$
D=\frac{\lambda K}{\beta \cos \theta},
$$

where $D$ is the estimated crystallite size, $\beta$ the FWHM (full width half maximum) and $K$ is a constant having value 0.94 (Dinnebier et al 2008). Figures 3 and 4 show that lattice parameters and crystallite size increase as a function of annealing temperature. It means that crystallite size of $\mathrm{Co}_{0.5} \mathrm{Mn}_{0.5} \mathrm{Fe}_{2} \mathrm{O}_{4}$ is sensitive to temperature. Annealing generally removes the lattice defects and strains but sometimes binds the crystallites in clusters and

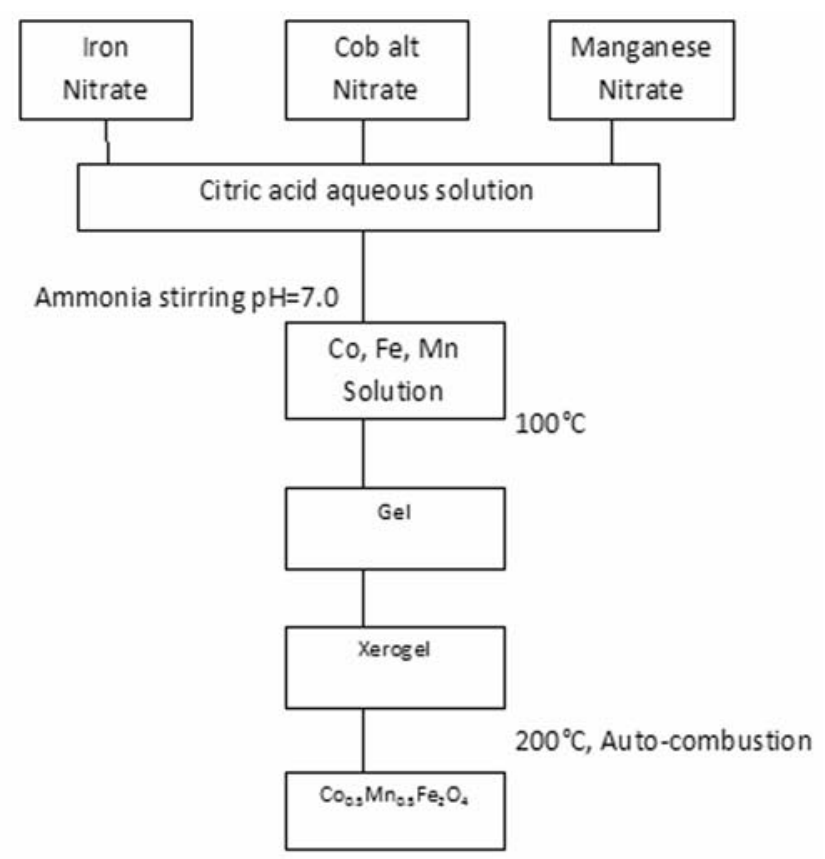

Figure 1. Flow chart for fabricating $\mathrm{Co}_{0.5} \mathrm{Mn}_{0.5} \mathrm{Fe}_{2} \mathrm{O}_{4}$ ferrites by combustion method.

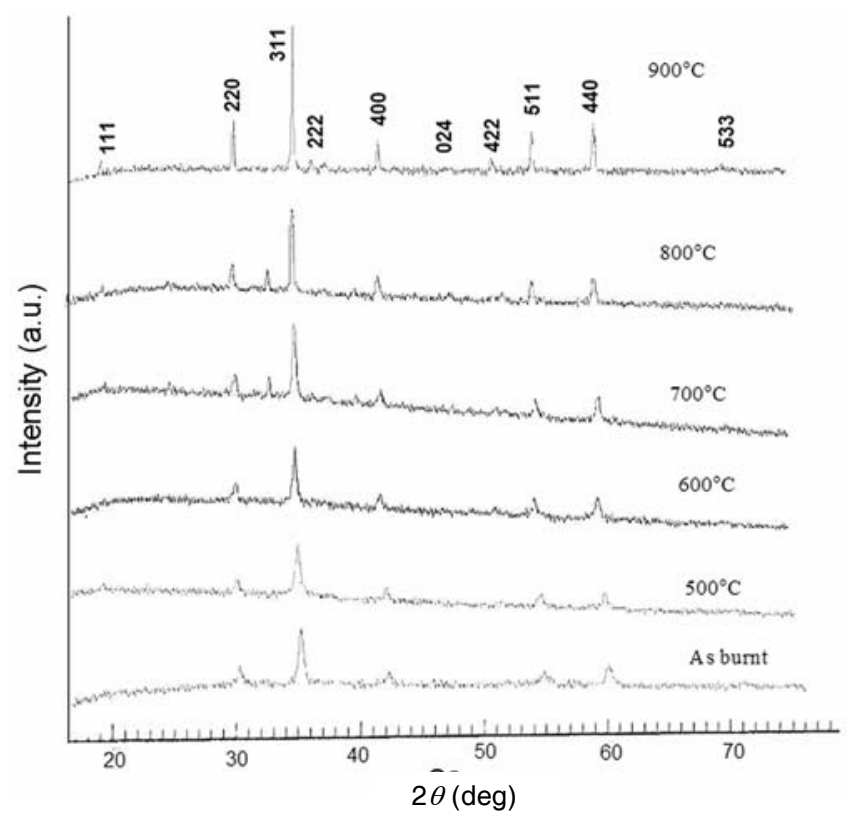

Figure 2. XRD patterns of $\mathrm{Co}_{0.5} \mathrm{Mn}_{0.5} \mathrm{Fe}_{2} \mathrm{O}_{4}$, as-burnt and annealed at 500,600, 700, 800 and $900^{\circ} \mathrm{C}$. 
increases their size (Raming et al 2002). Shobana et al (2009) have also reported the same composition but they showed amorphous behaviour of as-burnt powder, instead of crystalline. In our case, both as-burnt and annealed powders are shown to possess crystalline behaviour, contrary to previous results.

To elucidate the magnetic properties of as-burnt and the annealed samples, vibrating sample magnetometry was used and the results are shown in figure 5. The maximum applied magnetic field was $10 \mathrm{kOe}$ and measurements were carried out at room temperature. The measured parameters included temperature-dependent saturation magnetization $\left(M_{\mathrm{s}}\right)$ and coercivity $\left(H_{\mathrm{c}}\right)$. The results are presented in table 1 .

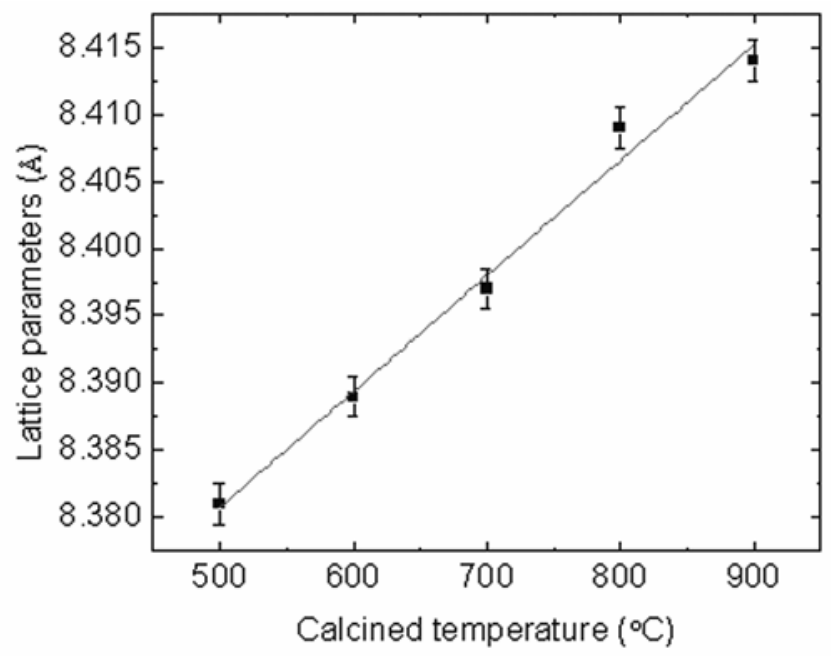

Figure 3. Variation of lattice parameters with annealing temperature.

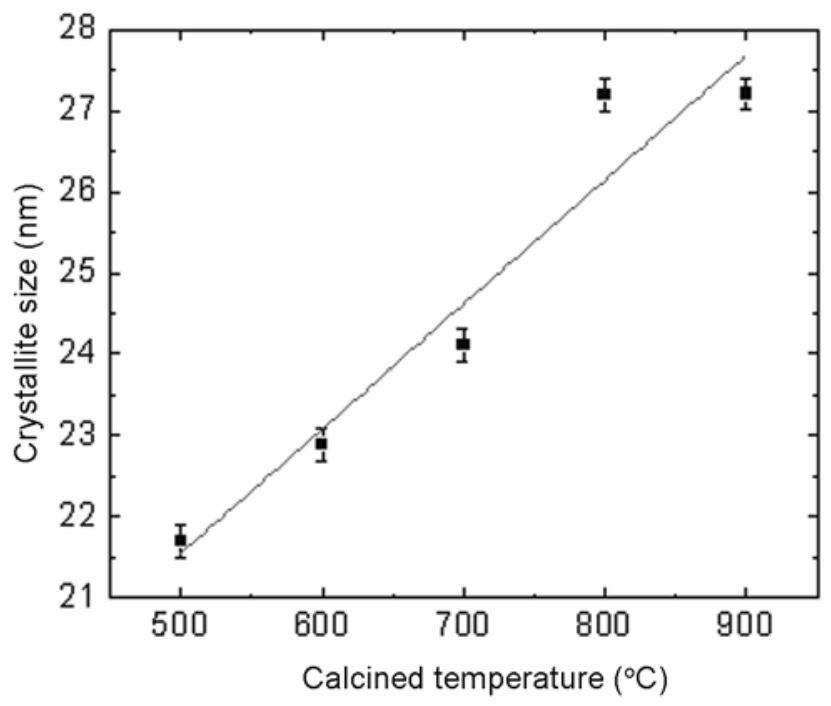

Figure 4. Variation of crystallite size with annealing temperature.
Figures 6 and 7 reveal that with the increase in annealing temperature, crystallite size increases whereas coercivity first increases from 1100 to 1470 Oe and then decreases from 1470 to 334.9 Oe. Furthermore, the saturation magnetization remains within the range of 20$50 \mathrm{emu} / \mathrm{g}$. The maximum value of coercivity of $1470 \mathrm{Oe}$ is obtained at $600^{\circ} \mathrm{C}$ with a crystallite size of $23 \mathrm{~nm}$. This behaviour may be due to the expected cross-over from single-domain to multi-domain behaviour with increasing size (Maaz et al 2007), or due to the combination of surface anisotropy and thermal energies. The first effect is expected only in $\mathrm{CoFe}_{2} \mathrm{O}_{4}$ having a critical particle size close to $50 \mathrm{~nm}$ (Schuele et al 1963; Berkowitz and Schuele 1959), which is higher than the critical size of $23 \mathrm{~nm}$ that we observed. The initial increase of coercivity with increasing crystallite size is due to the dominant role of surface anisotropy as compared to bulk anisotropy (Shobana et al 2009).

Figure 7 shows the variation of coercivity as a function of crystallite size at room temperature. As the crystallite size increases, the value of coercivity also increases, reaches a maximum value and then decreases. This variation of coercivity with crystallite size can be explained on the basis of domain structure and crystallite size. It is well-known that the size and configuration of magnetic domains have a significant effect on the coercivity. For example, our observed variation in the coercivity can be attributed to the cross-over between multi-domain and single-domain configurations. The variation of coercivity with particle or crystallite size (Lavcevic and Turkovic 2002) in the multi-domain configuration is expressed as (Berkowitz and Schuele 1959)

$$
H_{\mathrm{c}}=a+\frac{b}{D}
$$

where $a$ and $b$ are constants and $D$ is the diameter of the particle, indicating that as the particle diameter increases, the multi-domain coercivity decreases. This is corroborated in figure 7 , where the crystallite size exceeds the critical dimensions $(\approx 24 \mathrm{~nm})$.

On the other hand, in the single-domain region, which occurs when the crystallite size is smaller than a critical value, the variation of coercivity is expressed as (George et al 2006)

Table 1. Saturation magnetization $\left(M_{\mathrm{s}}\right)$, coercivity $\left(H_{\mathrm{c}}\right)$ and crystallite size as a function of annealing temperature.

\begin{tabular}{lcrc}
\hline $\begin{array}{l}\text { Annealing } \\
\text { temperature }\left({ }^{\circ} \mathrm{C}\right)\end{array}$ & $M_{\mathrm{s}}(\mathrm{emu} / \mathrm{g})$ & $H_{\mathrm{c}}(\mathrm{Oe})$ & $\begin{array}{c}\text { Crystallite } \\
\text { size }(\mathrm{nm})\end{array}$ \\
\hline 500 & $69 \cdot 0$ & $1056 \pm 50$ & $21 \cdot 7 \pm 0 \cdot 2$ \\
600 & $18 \cdot 2$ & $1470 \pm 40$ & $22 \cdot 9 \pm 0 \cdot 2$ \\
700 & $46 \cdot 7$ & $976 \pm 30$ & $24 \cdot 1 \pm 0 \cdot 2$ \\
800 & $33 \cdot 6$ & $880 \pm 30$ & $27 \cdot 2 \pm 0 \cdot 2$ \\
900 & $52 \cdot 0$ & $335 \pm 30$ & $27 \cdot 2 \pm 0 \cdot 2$ \\
\hline
\end{tabular}



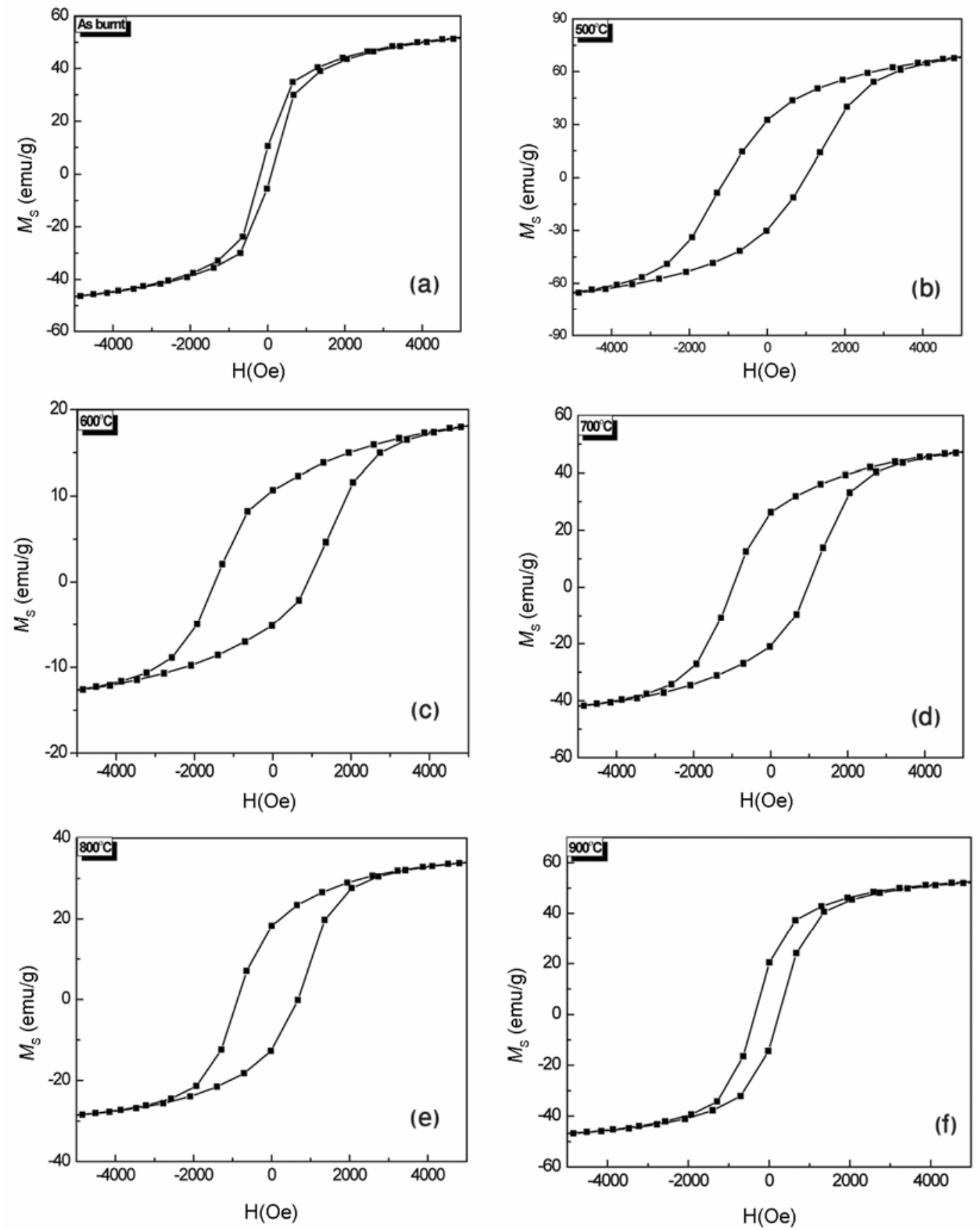

Figure 5. Room temperature magnetic properties of $\mathrm{Co}_{0.5} \mathrm{Mn}_{0.5} \mathrm{Fe}_{2} \mathrm{O}_{4}$ : (a) as-burnt and annealed at different temperatures: (b) $500^{\circ} \mathrm{C}$, (c) $600^{\circ} \mathrm{C}$, (d) $700^{\circ} \mathrm{C}$, (e) $800^{\circ} \mathrm{C}$ and (f) $900^{\circ} \mathrm{C}$.

$$
H_{\mathrm{c}}=g-\frac{h}{D^{3 / 2}},
$$

where $g$ and $h$ are constants showing that below the critical crystallite dimension, the coercivity increases with particle diameter. The trend of increasing and decreasing coercivities is quite evident in figure 7 , indicating the cross-over from single-domain to multi-domain configuration of the nanoparticles.

\section{Conclusions}

Nanocrystalline $\mathrm{Co}_{0.5} \mathrm{Mn}_{0.5} \mathrm{Fe}_{2} \mathrm{O}_{4}$ are synthesized by sol-gel auto-combustion method after adjusting the metal nitrate: citric acid ratio. The combustion process is simple, single step and an economical route for the production of nanocrystalline powder. The structural and magnetic properties were studied as a function of annealing temperature. The unit cell parameter $a$ and crystallite 


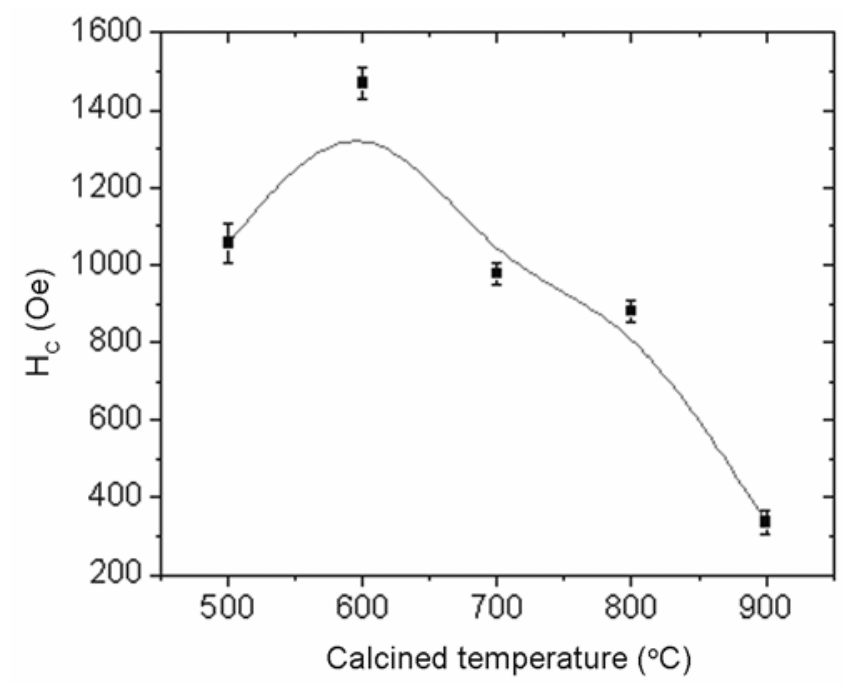

Figure 6. Variation of coercivity with annealing temperature.

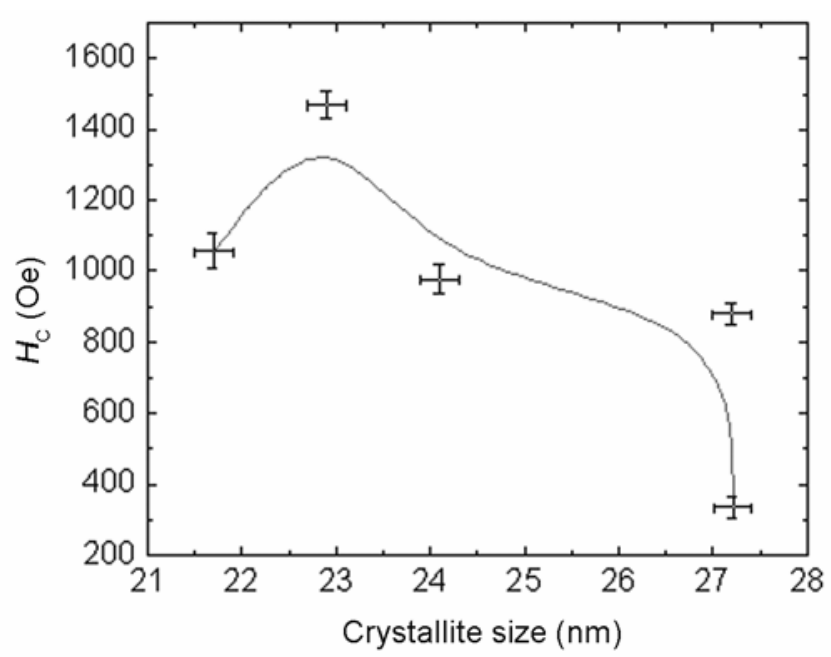

Figure 7. Coercivity as a function of crystallite size.

size $D$ increase linearly with an increase in temperature. Both as-burnt and annealed powders show crystalline behaviour. A maximum coercivity of about 1470 Oe with an average crystallite size $23 \mathrm{~nm}$ was obtained at $600^{\circ} \mathrm{C}$, which is higher than the value reported earlier (Shobana et al 2009). Furthermore, no significant change occurs in saturation magnetization as a function of annealing temperatures.

\section{References}

Abe M and Gomi M 1990 J. Magn. Magn. Mater. 84222

Berkowitz A E and Schuele W J 1959 J. Appl. Phys. 30 1345

Bouet L, Namikawa Tailhades P and Rousset A 1996 J. Magn. Magn. Mater. 153389

Caltun O, Rao G S N, Rao K N, Parvatheeswara Rao, Kim C G, Kim C O, Dumitru I, Lapu N and Chiriac H 2007a Sens. Lett. 545

Caltun O, Rao G S N, Rao K N, Parvatheeswara Rao, Dumitru I, Kim C O and Kim C G 2007b J. Magn. Magn. Mater. 316 e618

Chen Y, Synder J E, Schwichterberg C R, Dennis K W, McCullum R W and Jiles D C 1999 IEEE Trans. Magn. 35 3552

Cullity B D and Stock S R 2007 Elements of X-ray diffraction analysis (Pearson Education)

Daval J and Bechevet B 1994 J. Magn. Magn. Mater. 12998

Dinnebier RE and Billinge S J L 2008 Powder diffraction theory and practice (London: RSC Publishing)

George M, Nair S S, John A M, Joy P A and Anantharaman M R 2006 J. Phys. D, Appl. Phys. 39900

Lavcevic M L and Turkovic A 2002 Scr. Mater. 46501

Lee J E, Park J Y, On Y J and Kim C S 1992 J. Appl. Phys. 7 5926

Liu J 2005 Photonic devices (Cambridge: Cambridge University Press)

Maaz K, Mumtaz A, Hasanain S K and Ceylan A 2007 J. Magn. Magn. Mater. 308289

Mali A and Ataie A 2005 Scr. Mater. 531065

Martens J W D, Peeters W L, Van Noort H M and Erman M 1985 J. Appl. Chem. Solids 46411

Paulsen J A, Ring A P, Lo C C H, Synder J E and Jiles D C 2004 March Meeting Montreal (Quebec, Canada) W 27-5

Raming T P, Winnusbst A J A, Van Kats C M and Philipse P 2002 J. Colloid. Interf. Sci. 249346

Schuele W W, Deet Screek Y D, Kuhn W W, Lamprey H and Scheer C (eds) 1963 Ultrafine particles (New York: Wiley) p. 218

Shimokawa K, Dohnomal H, Mukai T, Yamada H, Matsuda H and Daimo M 1996 J. Magn. Magn. Mater. 154271

Shobana M K, Shankar S and Rajendran V 2009 Mater. Sci. Commun. 11310

Srinivas G and Shin S C 1996 Appl. Phys. Lett. 693086

Suzuki K and Yamazaki T 1988 Jpn. J. Appl. Phys. 27361

Suzuki T 1991 J. Appl. Phys. 694756

Zhou B, Zhang Y W, Liao C S, Cheng F X, Yan C H, Chen L Y and Wang S Y 2001 Appl. Phys. Lett. 791849 